\title{
IMPACT OF STUDENTS' PERCEIVED QUALITY OF DISTANCE EDUCATION ON STUDENT SATISFACTION WITH SPECIAL REFERENCE TO UNDERGRADUATE STUDENTS OF BACHELOR OF MANAGEMENT STUDIES DEGREE PROGRAMME, THE OPEN UNIVERSITY OF SRI LANKA
}

\author{
Abeykoon M.W.M and De Alwis A.C \\ mekhalaabeykoon@yahoo.com,dealwisac@gmail.com
}

\begin{abstract}
Distance education becomes more accepted as a legitimate form of education and as colleges and universities attempt to meet the growing demand for courses and programmes for distance learners, one major concern that attracts the attention is the aspect of quality. The primary issue for distance learning institutions, like for conventional ones, is quality and the assurance that students are being provided with the best possible education or training with the highest possible standards. Purpose of this study was to analyze the construct of quality as perceived by distance learners of Bachelor of Management Studies program at the Open University of Sri Lanka and the influence of this perception on the students' satisfaction. The study focused on identifying students perceptions of key dimensions that define the construct of quality from students' perspective. A questionnaire was used as the key tool of data collection. Descriptive and correlational statistics were the main tools used in the study. Results of the study clearly indicated that all dimensions except perception on quality of faculty were significantly correlated with students' satisfaction. The study conclude that institutions are required to pay attention to factors such as quality of pedagogy, learner support, technological and even infrastructure as measure of meeting students' quality expectations.
\end{abstract}

Key Words: Distance Education, Perceived Quality, Student Satisfaction

\section{INTRODUCTION}

Open and Distance Education (ODE) system has been gaining widespread popularity over the years, and the advancement in technology has led the emergence of distance education as an alternative to conventional mode of teaching and learning. Distance Education (DE) is planned learning that normally occurs in a different place from teaching and as a result requires special techniques of course design, special instructional techniques, special method of communication by electronics and other technology, as well as special organizational and administrative arrangements (Moore \&Kearsley, 2005).

The distance education mode was adopted 
by many universities to meet the evergrowing demand of those students who lacked means to pursue higher education through the regular stream.

Accordingly, one of the key discussions that have attracted interest is the quality and quality assurance in Distance education courses. Even though quality in distance education has largely and often been studied from national and institutional administrative and faculty stand points very few studies have analysed quality in DE from the learners' perspectives.

\subsection{Background of the Study}

During the last few decades, Distance Education (DE) has progressed very rapidly in the developed and some developing countries (e.g. UK, Turkey, Thailand, India, Pakistan and Sri Lanka). The Open Universities of these countries provide academic and instructional supports to the learners with the means of being able to communicate through voice, video and data, in real time, with tutors using modern ICTs and participating in face-to-face tutorial sessions.(Jahan, Habib, \&Akhtar,2012)

When it comes to the education system in Sri Lanka it offers several options for secondary school graduates. University Education is organized under the University Grants Commission (UGC) and mainly consists of two types of universities, state universities and private universities/institutes. State universities offer undergraduate degree programmes in the form of Internal (oncampus) full-time and External (distance learning) full-time or part-time. The OUSL degrees and external degrees (ED) are the two types of DE offered by state Universities

The term 'distance learning', as used in Sri Lanka, referred to two modes of education where the teacher and the students are separated by time and space at least for part of the duration of a course: at the very beginning, it meant a course of study totally delivered through correspondence; in more recent times, and mix of paper-based faceto-face instruction supplemented by selfaccess work by the students.

\subsection{Problem Identification}

As distance education becomes more accepted as a legitimate form of education and as colleges and universities attempt to meet the growing demand for courses and programmes for distance learners, one major concern is the aspect of quality. According to Dharanajan (2002), the primary issue for distance learning institutions, like for conventional ones, is quality and the assurance that students are being provided with the best possible education or training with the highest possible standards.

One of the key discussions that have attracted interest is the quality and quality assurance in Distance education courses. Even though quality in distance education has largely and often been studied from national and institutional administrative and 
faculty stand points very few studies have analysed quality in DE from the learners' perspectives.

Accordingly, a research conducted by Sumaedi, Bakti, \& Metasar ,(2011) on the Effect of Students' Perceived Service Quality and Perceived Price on Student Satisfaction, found that student perceived quality has a positive significant effect toward student satisfaction. Further it implies, any increase in student perceived quality will result in an increase of student satisfaction.

In addition to that another study conducted by Mbwesa (2014), on 'Students' Perceived Quality of Distance Education Courses as a Correlate of Learner Satisfaction: A Case Study of the Bachelor of Education Arts Program, University of Nairobi, Kenya" clearly indicated that the theory predictor variables Students' Perception of the quality of Pedagogy (SPQP), Students' Perception on the Quality of Infrastructure (SPQI), Students Perception on the Institutional Credibility(SPQC), and Students' Perception on the Quality of Evaluation (SPQE ) were all positively correlated with perceived students satisfaction with the DE course. According to that study, learners particularly seemed to value fair and clear learning assessment guidelines and periodic students' evaluation of teaching and learning. The study points to the conclusion that institutions must pay attention to factors such as quality of pedagogy, learner support, technological and even physical infrastructure as a measure of meeting students 'quality expectations.

According to Arbaugh , 2000 as cited in Alavi, Wheeler, \& Valacich, 1995; Alavi et al., 1997; Warkentin, Sayeed, \& Hightower, 1997. Similarly, student satisfaction with related to distance education draws major attention of researches where previous studies indicate that there is significant influence of studnets' perception of quality influence student satisfaction. Some studies emphasized that, Student satisfaction has become a very important strategic issue for universities offering distance learning.

Therefore, the present study intends to identify the impact of students' perceived quality of distance education on student satisfaction: with special reference to undergraduate students of Bachelor of Management Studies Degree Programme conducted by the department of Management studies, The Open University of Sri Lanka (OUSL).

The main issue which is going to be addressed in this research is how the perceived quality of Distance Education influences on Student Satisfaction.

Therefore Purpose of the study is to analyse the construct of quality as perceived by distance learners enrolled for a Bachelor of Management Studies program at the OUSL and the influence of this perception on the students' satisfaction with the DE course. In 
Particular, the analysis focused on identifying students' perceptions of different dimensions that define the construct of quality in DE from their perspective and how this influences students' satisfaction.

\subsection{Objectives of the Study}

The main objective of the study is to identify the impact of Student's perceived quality of Distance Education influences on Student Satisfaction.

\subsubsection{Specific Objectives}

To identify the level of Student Satisfaction regarding the course

To identify the level of Students' perceived quality of Distance Education

To analyze the relationship between Students 'perceived quality of Distance Education on Student Satisfaction.

To provide suggestions for increasing student satisfaction which is baked by high level of perceived quality

\subsection{Research Questions}

Accordingly following research questions were address in the study.

What is the level of Student Satisfaction regarding the course?

What is the level of perceived quality regarding the course?

Is there any relationship between Students 'perceived quality of Distance Education on Student Satisfaction?

To what extent does students perception of the quality of DE course influence students' satisfaction?

\subsection{Significance of the Study}

One of the major importances of the study is the understanding of how students perceive quality in distance education will help course designers to further enhance the quality of the programme and for similar programmes by clearly understanding their intentions. And how they perceive different aspects of quality is important in further enhancing the quality of the course.

Furthermore identifying the level of satisfaction regarding the course is vital to further enhancement and to maintain students' satisfactorily. Because according to the findings of the study it would reveal their level of satisfaction which will help to retain and attract students for the course. And the recommendations are important in maintaining/improving the satisfaction level of the student.

In addition to that, as there are few studied conducted in the perspective of students' with regard to how they perceive quality, this study might be helpful to fill the gap exists in the research area.

\section{LITERATURE REVIEW}

A research conducted by Sumaedi, Bakti, and Metasar , (2011) on the Effect of Students' Perceived Service Quality and Perceived Price on Student Satisfaction, found that student perceived quality has a positive significant effect toward student satisfaction. Further it implies, any increase in student perceived quality will result in an increase of student satisfaction. 
According to Mbwesa, (2014) institutions must pay attention to factors such as quality of pedagogy, learner support technological and even physical infrastructure as a measure of meeting students 'quality expectations

\section{METHODOLOGY}

The methodology applied in this study is the deductive approach.

The main objective of the study was to identify the impact of Student's perceived quality of Distance Education on Student Satisfaction. In addition to that the study aimed to identify the level of student satisfaction regarding the course and the level of Students' perceived quality of Distance Education and the relationship between Students 'perceived quality of Distance Education on Student Satisfaction

\subsection{Population and Sample}

Population of the study consists of 2030 students who've registered for the Bachelor of management Studies (BMS)

Degree programme at OUSL. The sample of the study consists of 300 students randomly selected from the population. Simple random sampling technique was used in selecting the sample from the population.

\subsection{Reliability Test}

Cronbach's Alpha test was used to test the internal consistency of the instruments. Test results indicated that, the alpha coefficients of all variables are above 0.7 which was considered that the items have relatively high internal consistency.

\subsection{Conceptual Framework}

The conceptual model adopted in this study was highly influenced by the ideas of Jung 2011 who studied Asian learners' perceptions about the quality of $\mathrm{DE}$ and examined gender differences in such perceptions. Basing ideas from Asian countries' QA systems for DE, Jung developed 10 categories model that defined different dimensions of quality as perceived by the distance learner. Based on the model developed by Jung, 2011, another researcher has developed six dimensional framework to study Students 'Perceived Quality of Distance Education Courses as a Correlate of Learner Satisfaction, which composed six dimensional model which includes following.

- Perception of the Quality of Pedagogy (SPQP)

- Perception on Learner Support Quality (SPQL)

- Perception of the quality of Faculty (SPQF)

- Perception on the Quality of Infrastructure (SPQI)

- Perception on the Institutional Credibility(SPQC)

- Perception on the Quality of Evaluation (SPQE)

Accordingly, researcher has adopted the conceptual framework developed by Mbwesa, (2014) in carrying out the present study. Figure 3.1 depicts the Conceptual Framework of the study

Issue I - 2016 


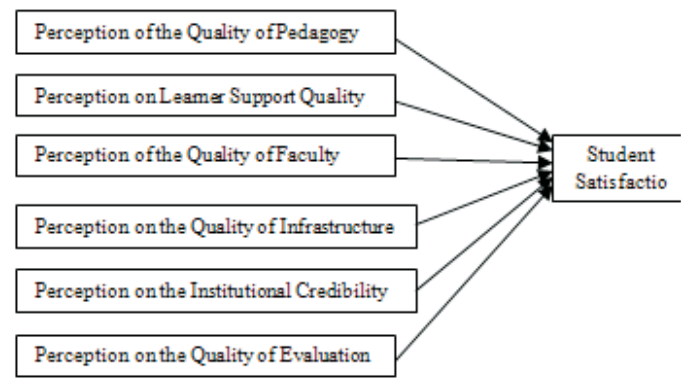

Source: Mbwesa, (2014)

Figure 3.1 Conceptual Framework

\subsection{Working Definitions of variables Perception of the Quality of Pedagogy}

SPQP Refers to policies and guidelines that help ensure and maintain the quality of course development processes, materials, and resources, and the course content's adaptability to learners Jung, (2012).

\section{Perception on Quality of Learner support}

SPQL Refers to the policy and guidelines for technical, financial, psychological, social, and administrative support, flexible payment, and appeal mechanisms Jung, (2012).

\section{Perception of the Quality of Faculty}

SPQF Refers to policies and procedures for training support during course development and delivery and faculty welfare. Jung, (2012).

Perception on the Quality of Infrastructure

SPQI Refers to the policies and measures, which ensure the reliability and security of technology systems as well as the provision of physical spaces. Jung, (2012).

\section{Perception on Institutional credibility}

SPQC Refers to the status of acquiring both national and international accreditations, showing strong leadership, and guaranteeing member qualifications that promote a DE institution's public credibility Jung, (2012).

\section{Perception on Quality of Evaluation}

SPQE Refers to activities and policies concerned with students' learning assessment feedback as well as various stakeholder evaluations. Jung, (2012)

\section{Student Satisfaction (SS)}

Student satisfaction is a short-term attitude, derived from the evaluation of the received education service. Elliot and Healy (2001)

\subsection{Hypotheses Development}

According to the study framework, developed the following hypotheses were constructed which will be tested in the study.

Hypothesis 1: Relationship between perceptions on the quality of pedagogy and student satisfaction

Hypothesis 2: Relationship between perception on quality of learner support and student satisfaction. 
Hypothesis 3: Relationship between perception on the quality of faculty and student satisfaction

Hypothesis 4: Relationship between perception on the quality of infrastructure and student satisfaction

Hypothesis 5: Relationship between perceptions on the Institutional Credibility and student satisfaction

Hypothesis 6: Relationship between perceptions on the quality of evaluation and student satisfaction

\section{DATA ANALYSIS}

Data were analyzed using descriptive statistics and inferential statistics. Mean value of the responses and frequency distribution was used to assess the level of student satisfaction and the level of Students' perceived quality.

Correlation analysis was used in analyzing the relationship between variables. And regression analysis was used to identify the impact of Student's perceived quality of Distance Education on Student Satisfaction.

In order to obtain data for the analysis, developed questionnaire was distributed to the sample of 300 undergraduate students of BMS Degree programme. However, only 242 respondents submitted the questionnaire back. Accordingly the response rate is $80.66 \%$.

\section{FINDINGS}

To identify the level of student satisfaction mean value was taken. Frequency was used to count how many respondents gave a particular answer to each question. Percentage was used to determine the fraction of people who gave a particular response. Table 5.1 depicts the Level of Student Satisfaction regarding the course.

Table 5.1 Level of Student Satisfaction Figure 5.1 Level of Student Satisfaction

\begin{tabular}{lll}
\hline $\begin{array}{l}\text { Level of } \\
\text { Satisfaction }\end{array}$ & Frequency & Percentage \\
\hline Moderate & 8 & $3.3 \%$ \\
High & 209 & $86.4 \%$ \\
Very High & 154 & $10.3 \%$ \\
Total & 242 & $100 \%$ \\
\hline
\end{tabular}

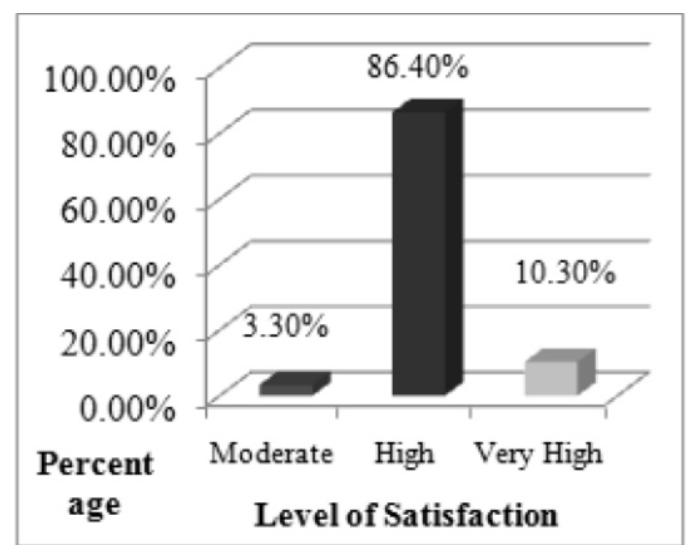

In the study it aimed to identify level of Perceived quality regarding the course. To measure the perceived quality, six dimensions of perceived quality was identified and level of quality of each dimensions were identified using the mean value Following Table 5.2 summarizes the 
levels of perceived quality in each dimension identified to measure the perceived quality in $\mathrm{DE}$.

Table 5.2 Level of Perceived Quality Analysis indicated that, Majority of respondents perceived all dimensions including, SPQP, SPQF, SPQL, SPQI, SPQE and SPQC are of high quality.

\begin{tabular}{|c|c|c|c|}
\hline \multirow[t]{2}{*}{ Item } & \multicolumn{3}{|c|}{$\begin{array}{l}\text { Level of Perceived } \\
\text { Quality }\end{array}$} \\
\hline & $\begin{array}{l}\text { Mod } \\
\text { erate }\end{array}$ & High & $\begin{array}{l}\text { Very } \\
\text { High }\end{array}$ \\
\hline $\begin{array}{l}\text { Perception on } \\
\text { Quality of } \\
\text { Pedagogy (PQP) }\end{array}$ & 0.8 & 78.9 & 20.2 \\
\hline $\begin{array}{l}\text { Perception on } \\
\text { Learner } \\
\text { Support } \\
\text { Quality } \\
\text { (SPQL) }\end{array}$ & 12.8 & 80.2 & 7.0 \\
\hline $\begin{array}{l}\text { Perception on } \\
\text { Quality of the } \\
\text { Faculty (PQF) }\end{array}$ & 13.2 & 71.5 & 15.3 \\
\hline $\begin{array}{l}\text { Perception on the } \\
\text { Quality of } \\
\text { Infrastructure } \\
\text { (SPQI) }\end{array}$ & 24.8 & 68.6 & 6.6 \\
\hline $\begin{array}{l}\text { Perception on the } \\
\text { Institutional } \\
\text { Credibility (SPQC) }\end{array}$ & 7.4 & 61.6 & 31 \\
\hline $\begin{array}{l}\text { Perception on the } \\
\text { Quality of } \\
\text { Evaluation (SPQE) }\end{array}$ & 10.7 & 82.2 & 7.0 \\
\hline
\end{tabular}

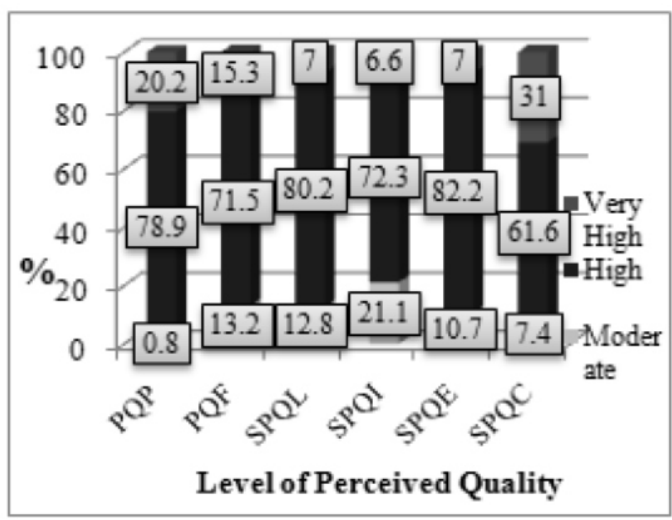

Figure 5.2 depicts the summary of Perceived quality of each dimension.

\section{Hypotheses Testing}

According to the Results of the hypothesis testing all hypotheses except perception on faculty quality, the alternative hypotheses were accepted. All dimensions except perception on faculty quality have moderate positive relationship with student satisfaction. Perception on faculty quality indicated weak positive relationship with student satisfaction. It was found that perception on quality of the faculty and student satisfaction is not significantly correlated with student satisfaction (Sig $=.739$ ) It can be identified as a positive weak relationship as the Pearson Correlation coefficient value $r=0.02$ which lies in the range of $0.0-0.25$.Accordingly the null hypothesis was accepted and the alternative hypothesis was rejected 
Table 5.3: Summarizes the hypothesis testing results of the study.

\begin{tabular}{lllll}
\hline $\begin{array}{l}\text { Hypot } \\
\text { hesis }\end{array}$ & $\begin{array}{l}\text { Sig } \\
\text { valu } \\
\text { e }\end{array}$ & Hl & H0 \\
\hline $\begin{array}{l}\text { Hypoth } \\
\text { esis 1 }\end{array}$ & .000 & 0.510 & Accepted & Rejected \\
$\begin{array}{l}\text { Hypo } \\
\text { thesis }\end{array}$ & .000 & 0.552 & Accepted & Rejected \\
$\begin{array}{l}\begin{array}{l}\text { Hypoth } \\
\text { esis 3 }\end{array} \\
.739\end{array}$ & 0.022 & Rejected & Accepted \\
\hline $\begin{array}{l}\text { Hypoth } \\
\text { esis 4 }\end{array}$ & .000 & 0.542 & Accepted & Rejected \\
$\begin{array}{l}\text { Hypoth } \\
\text { esis 5 }\end{array}$ & .000 & 0.565 & Accepted & Rejected \\
$\begin{array}{l}\text { Hypoth } \\
\text { esis 6 }\end{array}$ & .000 & 0.510 & Accepted & Rejected \\
\hline
\end{tabular}

All dimensions except perception on faculty quality have moderate positive relationship with student satisfaction. Perception on faculty quality indicated weak positive relationship with student satisfaction. It was found that perception on quality of the faculty and student satisfaction is not significantly correlated with student satisfaction (Sig =.739) It can be identified as a positive weak relationship as the Pearson Correlation coefficient value $r=$ 0.02 which lies in the range of $0.0-$ 0.25 .Accordingly the null hypothesis was accepted and the alternative hypothesis was rejected

The main objective of the study was to identify the impact of perceived quality of DE on student satisfaction. Accordingly, to what extent does perceived quality influences student satisfaction was analysed using regression analysis. Following table depicts the output of the regression analysis

\begin{tabular}{lllll}
\hline $\begin{array}{l}\text { Mod } \\
\text { el }\end{array}$ & $\mathrm{R}$ & $\begin{array}{l}\mathrm{R} \\
\text { Square }\end{array}$ & $\begin{array}{l}\text { Adjuste } \\
\mathrm{d} \mathrm{R} \\
\text { Square }\end{array}$ & $\begin{array}{l}\text { Std. Error } \\
\text { of the } \\
\text { Estimate }\end{array}$ \\
\hline & & & \\
1 & $.643(\mathrm{a})$ & .413 & .411 & 2.972 \\
\hline Mbweșa, 2014. Results of that indicated
\end{tabular}

Table 5.4 Regression Analysis.

The results indicate that, $41.3 \%$ variation in student satisfaction can be explained by the variance of perceived quality. The remaining $59.7 \%$ can be explained by other factors which are not included in the conceptual framework of the study

\section{Discussion}

Findings of the study revealed that, all variables used to measure perceived quality of DE (SPQP, SPQL, SPQF, SPQE, SPQC and SPQI) were positively correlated with student satisfaction. This is $\mathrm{s}$ also supported by previous study, which has indicated that 10 dimensions (Faculty support, Student support, Information \& publicity, Interactive tasks ,Institutional quality assurance mechanism, Institutional credibility, Course development, Teaching a\& learning Evaluation \& assessment and Infrastructure dimension)across supportive, pedagogical, and environmental domains are important in judging quality in distance education. (Jung, 2012, Mbwesa, 2014) 
Furthermore findings of the study revealed that all dimensions except perception on faculty quality have moderate positive relationship with student satisfaction. Perception on faculty quality indicated weak positive relationship with student satisfaction. This Finding is consistent with previous study of Mbwesa, (2014). Which indicate that there was a weak positive correlation between SPQF and SPS and which was not significant. This implies that SPQF does not have a strong influence on perceived students' satisfaction with the course (SPS).

Findings of the study further revealed that perception on quality of pedagogy and student satisfaction is significantly correlated with student satisfaction. It can be identified as a positive moderate relationship. This finding is not consistent with the previous study conducted by , 2014 . Results of that indicated that there was a weak positive correlation between SPQS and SPS.

When it comes to the perception on quality of learner support and student satisfaction, It was found that perception on quality of learner support and student satisfaction is significantly correlated with student satisfaction. This finding is not consistent with the previous study conducted by Mbwesa, 2014. As the Results indicated that there was a weak positive correlation between SPQS and SPS and implies that SPQL does not have a strong influence on perceived students' satisfaction with the course.

Findings on Institutional Credibility and student satisfaction revealed that perception on Institutional Credibility and student satisfaction is significantly correlated with student satisfaction. This is s also supported by previous study, which has indicated SPQI and SPS were positively correlated and which was significant which implies that SPQI does have a strong influence on perceived students 'satisfaction with the course (SPS).

When analyzing quality of evaluation and student satisfaction findings indicated that is significantly correlated with student satisfaction. This is supported by a previous study conducted by Jung, 2011. It reported that In the pedagogical domain, evaluation and assessment was the most powerful dimension in explaining DE quality. The learners saw fair and clear learning assessment guidelines and periodic students' evaluation of teaching and learning as particularly important. This Finding is also consistent with previous studies, which highlight the importance of evaluation and assessment in assuring the quality of elearning (Frydenberg, 2002; Lodzinski \& Pawlowski,2006).

Findings of perception on quality infrastructure and student satisfaction revealed that it is significantly correlated with student satisfaction. this finding is consistent with the findings of Mbwesa 
2014, where it indicated that there was a positive correlation between SPQI and SPS and which implies that SPQI does have a strong influence on perceived students' satisfaction with the course (SPS).

\section{REFERENCES}

Alavi, M., Wheeler, B. C., \& Valacich, J. S. 1995. Using IT to re-engineer

business education: an exploratory investigation of collaborative tele learning. MIS Quarterly, 19, 293-312.

Arbaugh, J. B. 2000a. Virtual classroom characteristics and student satisfaction in Internet-based MBA courses. Journal of Management Education, 24(1), 32-54.

Frydenberg, J. (2002). Quality standards in e-learning: A matrix of analysis. The

International Review of Research in Open and Distance Learning, 3(2). Retrieved

from http://www.irrodl.org/index.php/ irrodl/article/viewArticle/109/189

Jahan, M., Habib, R. I., \& Akhtar, S. (2012). ODE in Bangladesh compared with that in Sri Lanka and India. Asian Journal of Distance Education. The AsianSociety of Open and Distance Education, 10(1), 61-75.

Jung, I. (2011). The dimensions of elearning quality: from the learner's perspective. Educational Technology Research and Development, 59(4), 445-464.

Jung, I. (2012). Asian learners' perception of quality in distance education and gender differences. The International
Review of Research in Open and Distributed Learning, 13(2), 1-25.

Daranajan, G., (2002).Open and Distance Learning in Developing Economies, UNESCO Conference of Ministers of Education of African Member States, December 6

Elliot, K.M., Healy, M.A. (2001). Key factors influencing student satisfaction related to recruitment and retention. Journal of Marketing for Higher Education, 10(4), 1-11.

Mbwesa, J. K. (2014). Students' Perceived Quality of Distance Education Courses as a Correlate of Learner Satisfaction: A Case Study of the Bachelor of Education Arts Program, University of Nairobi, Kenya. International Journal of Social Science Studies, 2(2), 86-99.

Moore, M. G., \& Kearsley, G. (2005). Distance education: A systems view (2nd ed.). Belmont, CA: Thomson Wadsworth

Sumaedi, S., Bakti, I. G. M. Y., \& Metasari, N. (2011). The effect of students' perceived service quality and perceived price on student satisfaction. Management Science and Engineering, 5(1), 88-97. 